\title{
Antibody response in patients admitted to the hospital with suspected SARS-CoV-2 infection: results from a multicenter study across Spain
}

\author{
Ana Fuentes ${ }^{1}$ - Esther Serrano-Conde ${ }^{1}$ - Carolina Roldán ${ }^{2} \cdot$ Rafael Benito-Ruesca $^{3}$ - Gregoria Mejías ${ }^{4}$. \\ Antonio Sampedro ${ }^{5}$. Gabriel March-Roselló ${ }^{6} \cdot$ Isabel Fernández-Natal ${ }^{7}$. Juliana Esperalba ${ }^{8} \cdot$ Mario José Rodríguez $^{9}$. \\ Paula Martínez de Aguirre ${ }^{10}$. Carlos Salas ${ }^{11}$. María Lourdes Roc ${ }^{12} \cdot$ Luis Miguel Soria $^{13}$ • Mónica Parra-Grande ${ }^{14}$. \\ María Dolores Montero ${ }^{15}$ - Ricardo Fernández-Roblas ${ }^{16}$ • Francisco Franco-Álvarez de Luna ${ }^{17}$. Carmen Lozano ${ }^{18}$. \\ Federico García ${ }^{1}$ (iD
}

Received: 29 September 2020 / Accepted: 20 December 2020 / Published online: 29 January 2021

(C) The Author(s) 2021

\begin{abstract}
Aim To evaluate the serological response against SARS-CoV-2 in a multicenter study representative of the Spanish COVID pandemic.

Methods IgG and IgM + IgA responses were measured on 1466 samples from 1236 Spanish COVID-19 patients admitted to the hospital, two commercial ELISA kits (Vircell SL, Spain) based on the detection of antibodies against the viral spike protein and nucleoprotein, were used.

Results Approximately half of the patients presented antibodies ( $56.8 \%$ were $\operatorname{IgM}+\operatorname{IgA}$ positive and $43.0 \%$ were $\mathrm{IgG}$ positive) as soon as 2 days after the first positive PCR result. Serological test positivity increased with time from the PCR test, and 10 days after the first PCR result, $91.5 \%$ and $88.0 \%$ of the patients presented IgM + IgA and IgG antibodies, respectively.

Conclusion The high values of sensitivity attained in the present study from a relatively early period of time after hospitalization support the use of the evaluated serological assays as supplementary diagnostic tests for the clinical management of COVID-19.
\end{abstract}

Keywords COVID-19 $\cdot \mathrm{SARS}-\mathrm{COV}-2 \cdot \operatorname{IgG} \cdot \operatorname{IgM} \cdot \operatorname{IgA} \cdot$ Diagnosis

\section{Introduction}

Coronavirus disease 2019 (COVID-19) is a severe acute respiratory syndrome produced by a novel coronavirus (SARS-

Federico García

fegarcia@ugr.es

1 Hospital Universitario Clínico San Cecilio, Instituto de Investigación Ibs, Av, Innovación S/N, 18016 Granada, Spain

2 Complejo Hospitalario de Jaén, Jaén, Spain

3 Hospital Clínico Universitario Lozano Blesa, Zaragoza, Spain

4 Hospital Universitario de Burgos, Burgos, Spain

5 Hospital Universitario Virgen de las Nieves, Granada, Spain

6 Hospital Clínico Universitario de Valladolid, Valladolid, Spain

7 Complejo Asistencial Universitario de León, León, Spain

8 Hospital Universitario Valle de Hebrón, Barcelona, Spain

CoV-2) that has spread globally and very quickly since its first appearance in Wuhan, China, in December 2019 [1]. SARSCoV-2 is the seventh known coronavirus that infects humans; SARS-CoV, MERS-CoV, and SARS-CoV-2 can cause

9

10

Universidad de Navarra, Pamplona, Spain

11 Hospital Universitario Marqués de Valdecilla, Santander, Spain

12 Hospital Universitario Miguel Servet, Zaragoza, Spain

13 Hospital San Pedro, Logroño, Spain

14 Complejo Hospitalario Universitario de Albacete, Albacete, Spain

15 Hospital Universitario La Paz, Madrid, Spain

16 Hospital Universitario Fundación Jiménez Díaz, Madrid, Spain

17 Hospital Universitario Juan Ramón Jiménez, Huelva, Spain

18 Hospital Universitario Virgen del Rocío, Sevilla, Spain 
severe disease, whereas HKU1, NL63, OC43, and 229E are associated with mild respiratory illness [2]. The virus has a genome size of 30 kilobases that encodes multiple structural and nonstructural proteins. The structural proteins include the spike (S) protein, the envelope (E) protein, the membrane (M) protein, and the nucleocapsid $(\mathrm{N})$ protein.

The diagnostic approach to SARS-CoV-2 includes the detection of viral RNA by real-time PCR (RT-PCR). Different factors could contribute to false negative results of RNA tests with RT-PCR, such as insufficient amount of virus at the site of sample collection, incorrect sample collection or being outside in the viral replication time window [3-6]. Serological methods combined with PCR could be of help for increasing the sensitivity and accuracy of the diagnosis, especially in patients with negative RT-PCR results; serology may also help to identify asymptomatic and past infections. SARSCOV-2 serology undoubtedly helps to understand the immune status of the population and to evaluate viral spread [7]; hence, serology should be used for epidemiological studies to investigate the rate of asymptomatic infections and to better estimate morbidity and mortality [7]. Serological methods include binding and neutralization assays. Binding assays such as ELISAs are easily automatized, and they are very well adapted to a pandemic situation; neutralization assays require viral culture, and they must be performed in a facilities with higher biosecurity levels [8].

Preliminary studies have analyzed antibody responses against SARS-COV-2. Some authors [2, 9-12] found that IgM was detected on day 7 and peaked on day 28 , and $\operatorname{IgG}$ appeared by day 10 and peaked on day 49, while others [13] determined that seroconversion among 173 patients took place at median times of $12(\operatorname{IgM}), 14(\operatorname{IgG})$, and 11 (neutralizing antibodies) days. The duration and nature of SARSCoV-2 immunity is unknown. The timescale of protection is a critical determinant of the future impact of the pathogen. The presence or absence of protective immunity due to infection or vaccination (when available) will affect future transmission and illness severity and will allow the identification of individuals with protective immunity $[2,7,10,13,14]$.

Additional studies are needed to characterize how antiSARS-CoV-2 antibodies will change over prolonged periods of time. The present study presents data from a large series of samples covering both $\operatorname{IgG}$ and $\operatorname{IgM}+\operatorname{IgA}$ responses to two of the main viral antigenic proteins $(\mathrm{N}$ and $\mathrm{S})$.

\section{Materials and methods}

\section{Patients}

One thousand two hundred thirty-six patients screened for COVID-19 admitted to 18 Public and Private Spanish Hospitals (Clínica Universidad de Navarra, Complejo
Asistencial Universitario de León, Complejo Hospitalario Universitario de Albacete, Complejo Hospitalario de Jaén, Hospital Clínico Universitario Lozano Blesa, Hospital Clínico Universitario de Valladolid, Hospital Ramón y Cajal, Hospital San Pedro, Hospital Universitario Clínico San Cecilio, Hospital Universitario de Burgos, Hospital Universitario Fundación Jiménez Díaz, Hospital Universitario Juan Ramón Jiménez, Hospital Universitario La Paz, Hospital Universitario Marqués de Valdecilla, Hospital Universitario Miguel Servet, Hospital Universitario Valle de Hebrón, Hospital Universitario Virgen de las Nieves, and Hospital Universitario Virgen del Rocío) were studied. All patients were positive by RT-PCR; sex data were available for 513 men and 353 women; age data were available for 1066 patients, mean age 64 years, range $15-100$ years.

\section{Serum samples}

Samples were drawn on the same day or after the RT-PCR test was performed. Differences in days were due to clinical needs in the general management of the patients.

Single serum samples were obtained from 1054 patients, while multiple serum samples $(n=413)$ were obtained from 183 patients, comprising 1467 samples. The distribution of samples according to time from RT-PCR can be seen in Table 1. There were two samples available for 43 patients, the first collected before 4 days after PCR and the second collected 7-17 days after PCR.

\section{ELISAs}

Anti-SARS-CoV-2 IgG and IgM + IgA ELISAs (Vircell SL, Spain) were carried out according to the manufacturer's protocol. Reaction wells in both assays were coated with nucleocapsid and spike proteins. Serum samples were previously inactivated at $56^{\circ} \mathrm{C}$ for 30 minutes. Samples were immediately tested after inactivation or stored at $4{ }^{\circ} \mathrm{C}$ for no longer than 4 days before testing. The specificity declared by the manufacturer for the $\operatorname{IgG}$ and $\operatorname{IgM}+\operatorname{IgA}$ assays is $98.2 \%$ and $98.9 \%$, respectively, based on studies performed on prepandemic populations. Both ELISAs are qualitative; the $\operatorname{IgM}+\operatorname{Ig}$ A ELISA does not differentiate between both inmunoglobulins.

\section{RT-PCR assays}

RT-PCR from naso- and oro-pharyngeal swabs was performed after nucleic acid extraction with different commercial CE-approved assays. 
Table 1 Positive rates for IgG and IgA + IgM detection in 1466 serum samples from PCR-positive patients. The results are expressed as absolute frequencies (percentage shown in parentheses) of positive samples in each parameter or in both parameters at the same time

\begin{tabular}{lllllllll}
\hline Sample day $^{\text {a }}$ & $\begin{array}{l}\text { Total no. } \\
\text { of sera }\end{array}$ & IgG & IgM + IgA & $\begin{array}{l}\text { IgG and/or } \\
\text { IgM + IgA }\end{array}$ & Only IgG positive & $\begin{array}{l}\text { Only IgM } \\
\text { + IgA positive }\end{array}$ & $\begin{array}{l}\text { Both IgG and IgM } \\
\text { + IgA positive }\end{array}$ & $\begin{array}{l}\text { Both IgG and IgM } \\
\text { + IgA negative }\end{array}$ \\
\hline 0 & 326 & $135(41.4)$ & $154(47.2)$ & $187(57.4)$ & $19(5.8)$ & $38(11.7)$ & $116(35.6)$ & $153(46.9)$ \\
1 & 332 & $134(40.4)$ & $165(49.7)^{\mathrm{b}}$ & $180(54.2)$ & $21(6.3)$ & $52(15.7)$ & $113(34.0)$ & $146(44.0)$ \\
2 & 154 & $83(53.9)$ & $98(63.6)$ & $95(61.7)$ & $6(3.9)$ & $21(13.6)$ & $77(50.0)$ & $50(32.5)$ \\
3 & 106 & $61(57.5)$ & $68(64.2)$ & $69(65.1)$ & $8(7.5)$ & $15(14.2)$ & $53(50.0)$ & $30(28.3)$ \\
4 & 111 & $79(71.2)$ & $89(80.2)$ & $92(82.9)$ & $7(6.3)$ & $17(15.3)$ & $72(64.9)$ & $15(13.5)$ \\
5 & 51 & $40(78.4)$ & $42(82.4)$ & $39(76.5)$ & $2(3.9)$ & $4(7.8)$ & $38(74.5)$ & $7(13.7)$ \\
6 & 53 & $34(64.2)$ & $38(71.7)$ & $38(71.7)$ & $1(1.9)$ & $5(9.4)$ & $33(62.3)$ & $14(26.4)$ \\
7 & 50 & $37(74.0)$ & $42(84.0)$ & $41(82.0)$ & $1(2.0)$ & $6(12.0)$ & $36(72.0)$ & $7(14.0)$ \\
8 & 42 & $26(61.9)$ & $33(78.6)$ & $32(76.2)$ & $1(2.4)$ & $8(19.0)$ & $25(59.5)$ & $8(19.0)$ \\
9 & 30 & $20(66.7)$ & $23(76.7)$ & $23(76.7)$ & $1(3.3)$ & $4(13.3)$ & $19(63.3)$ & $6(20.0)$ \\
$10-16$ & 129 & $114(88.4)$ & $119(92.2)$ & $118(91.5)$ & $2(1.6)$ & $7(5.4)$ & $112(86.8)$ & $8(6.2)$ \\
$17-23$ & 40 & $36(90.0)$ & $36(90.0)$ & $38(95.0)$ & $1(2.5)$ & $1(2.5)$ & $35(87.5)$ & $3(7.5)$ \\
$24-30$ & 16 & $16(100)$ & $16(100)$ & $16(100)$ & $0(0.0)$ & $0(0.0)$ & $16(100)$ & 0 \\
$>30$ & 26 & $24(92.3)$ & $20(76.9)$ & $24(92.3)$ & $4(15.4)$ & $0(0.0)$ & $20(76.9)$ & $2(7.7)$ \\
\hline
\end{tabular}

${ }^{a}$ Days after the first positive PCR result

${ }^{\mathrm{b}} p=0.016$ compared to IgG (all other comparisons not significative)

\section{Statistical analysis}

Statistical analysis was performed with the help of the R program version 3.6.3 (2020-02-29) - "Holding the Windsock" Copyright (C) 2020 The R Foundation for Statistical Computing Platform: x86_64-w64-mingw32/x64 (64-bit). Borderline results were primarily interpreted as negative. The Wilcoxon-Mann-Whitney test was used for $\mathrm{p}$-value calculations. Data were graphically presented in box-andwhisker plots with boxes encompassing $90 \%$ of the data and whiskers presenting the $95 \%$ and $5 \%$ percentiles.

\section{Results}

\section{Anti-SARS-CoV-2 antibody kinetics}

The results from 1467 serum samples from PCR-positive patients referred to the collection date with respect to the first PCR-positive result of the patient are shown in Table 1. At day 0 , a higher reactivity was observed for $\operatorname{IgM}+\operatorname{IgA}$ (154 positive samples, $47.2 \%)$ than for $\operatorname{IgG}(135,41.4 \%)$, with 187 samples $(57.4 \%)$ with any serological marker. This tendency for a higher reactivity in the $\operatorname{IgM}+\operatorname{IgA}$ response only reached statistical significance at day $1(p=0.016)$, and could be seen during the first 16 days, with $84.0 \%$ of IgM $+\operatorname{IgA}$ positive results against $74.0 \%$ of $\mathrm{IgG}$ positive results at day 7 after PCR. After the third week, the proportion of positive results was similar in both parameters, while $\operatorname{IgG}$ was more prevalent in samples collected one month after PCR. Positive IgM + IgA together with positive IgG was the most frequently found pattern $(36.5 \%)$ at day 0 , followed by positivity to only IgM $+\operatorname{IgA}(11.7 \%)$ and positivity to only $\operatorname{IgG}(5.8 \%)$. Throughout all the time ranges studied and whenever a single marker was present, $\operatorname{IgM}+\operatorname{IgA}$ was more frequent than $\operatorname{IgG}$.

Figure 1 shows the evolution of $\operatorname{IgG}$ and $\operatorname{IgM}+\operatorname{IgA}$ over time. The proportion of positive cases was higher for IgM $+\operatorname{IgA}$ until day 24 , when positivity for both $\operatorname{IgG}$ and $\operatorname{IgM}$ was equal.

To better understand the kinetics of the antibody response, seroconversion was studied in 43 patients for whom two samples were available (T1: samples collected not later than 4 days post PCR; T2, second samples collected between 7 and 17 days post $\mathrm{PCR}$ ). The results are shown in Table 2. IgG was detected in 15 (34.9\%) of the T1 samples, while IgM + IgA was detected in $23(53.5 \%)$. IgG and IgM + IgA were detected in $35(81.4 \%)$ and $40(93.0 \%)$ of the $\mathrm{T} 2$ samples, respectively. Twenty patients seroconverted for IgG and 19 for IgM + IgA, whereas 2 patients did not show seroconversion. The index means were $1.97(\operatorname{IgG})$ and $2.55(\operatorname{IgM}+\operatorname{IgA})$ for the acute infection samples and $3.04(\operatorname{IgG})$ and $3.15(\operatorname{IgM}+\operatorname{IgA})$ for the convalescent samples.

\section{Effect of age and sex on antibody responses to SARS- CoV-2}

PCR-positive patients were classified into four groups according to the results of the serological tests: only $\operatorname{IgG}$ positive, only IgM + IgA positive, positive in both tests or negative in both tests. Figure 2a shows the distribution of serological results by age group corresponding to the 1066 patients for 
Fig. 1 Dynamic trend of the positive rate for $\operatorname{IgG}$ and $\operatorname{IgM}+$ IgA in sera of RT-PCR-positive patients

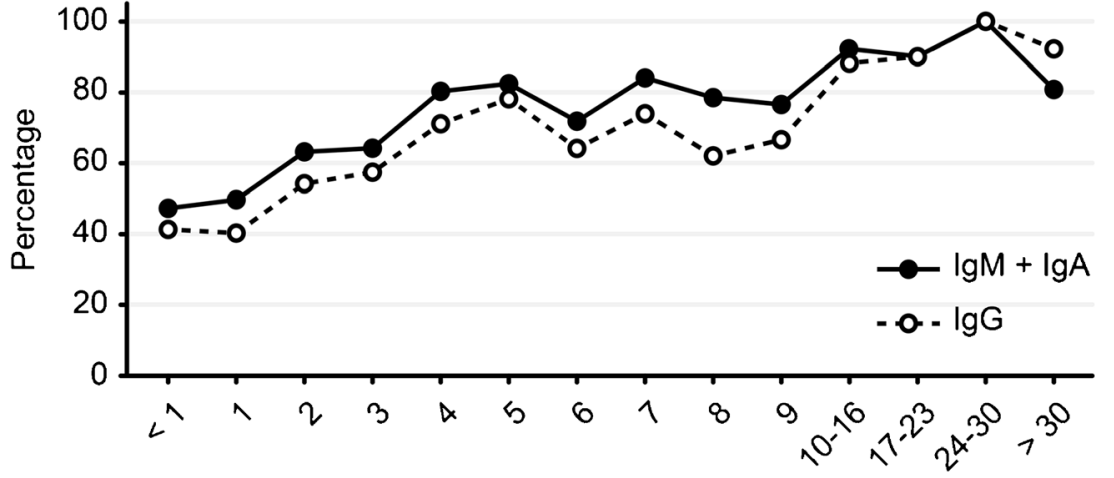

Days whom age data were available. The proportion of patients with negative serological responses for both tests increased with patient age. When these results were analyzed according to the time elapsed between the PCR and the serum collection (Fig. 2b and c), this effect could also be seen for samples collected early after the first PCR diagnosis, while most samples collected in the second week after PCR showed positive serological responses in all age groups.

Figure 3 shows the differences in serological results by age and sex. No significant differences were seen between men and women as a whole either for $\operatorname{IgG}$ or for $\operatorname{IgM}+\operatorname{IgA}$. Although differences between the sexes could be observed for some age groups, there was not a clear tendency that supported a higher serological response of men over women, and this result may reflect differences in the population sizes.

\section{Discussion}

The utility of serological tests to help in the diagnosis of COVID-19 was evaluated in a multicenter study with a large series of samples collected from 1236 patients in several

Table 2 Positive rates for $\operatorname{IgG}$ and $\operatorname{Ig} \mathrm{A}+\operatorname{IgM}$ detection in sera from selected patients for whom two samples collected at two different time points were available. Time ranges were $0-4$ days post PCR for first serum collection and 7-17 days post PCR for second serum collection

\begin{tabular}{lcc}
\hline Serological parameter & \multicolumn{2}{l}{ No. of positive sera (\%) } \\
\cline { 2 - 3 } & $0-4$ days & $7-17$ days \\
\hline IgG & $15(34.9)$ & $35(81.4)$ \\
IgM + IgA & $23(53.5)$ & $40(93.0)$ \\
Both IgG and IgM + IgA & $15(34.9)$ & $34(79.1)$ \\
IgG only & $1(2.3)$ & $1(2.3)$ \\
IgM + IgA only & $8(18.6)$ & $6(14.0)$ \\
Both negative & $19(44.2)$ & $2(4.7)$ \\
\hline
\end{tabular}

$T 1$ first serum, $T 2$ second serum
Spanish hospitals during the peak of the pandemic. In our study, we observed high values of sensitivity, especially for the $\operatorname{IgM}+\operatorname{IgA}$ test at early periods of time after hospitalization (61.7\% presented a positive serology in the first 4 days of the diagnosis, and $90.5 \%$ after the first week). We believe that our findings support the use of serological assays as supplementary diagnostic tests for the clinical management of COVID19. We also observed a decreased sensitivity of serology in older patients in samples collected early in the disease.

Two commercial kits were used to measure the $\operatorname{IgG}$ and $\operatorname{IgM}+\operatorname{Ig} \mathrm{A}$ responses against two major antigenic components of the virus, the $\mathrm{N}$ and $\mathrm{S}$ proteins. To our knowledge, few commercial tests are simultaneously based on both proteins. Studies with good performances for assays based either on the $\mathrm{N}$ protein $[15,16]$, the $\mathrm{S}$ protein $[7,13,17]$ or both antigens [9, 10, 14, 18] have been published. Another peculiarity of the assays used in the study is the inclusion of $\operatorname{IgA}$ together with $\operatorname{IgM}$ for early detection of the disease. Several studies have described a good sensitivity of this immunoglobulin class, better than that of $\mathrm{IgG}$, although with a lower specificity $[2,7,12,18,19]$. The specificity of the test was established by the manufacturer of the kit on the basis of samples collected from prepandemic populations (98.8\% CI 95\% 95.52-99.68). The high levels of sensitivity reported in the present study, above those reported in other studies $[17,20,21]$, may be related to the aforementioned special features of the assays used in the study: the use of two viral antigens and the inclusion of IgA.

The percentage of IgM + IgA-positive patients with IgGnegative levels was higher in samples collected at early stages of the disease, as can be expected for these immunoglobulin classes. However, we did not observe a decrease in IgM + IgA values, as has been shown by other authors [9], probably due to the low number of samples after hospital discharge included in the study. Positivity of the serological tests increases with time, reaching values close to $100 \%$ in samples taken 10 days or more after the first PCR result. Conversely, in studies carried out with MERS patients, $20 \%$ of the patients did not show 
a

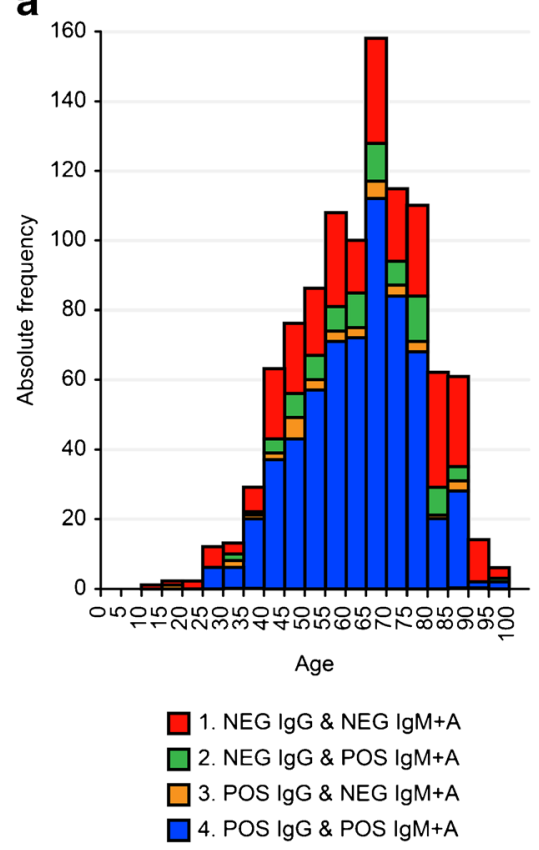

Fig. 2 Serology test results for positive PCR patients grouped by age. Bar heights represent absolute frequencies. a Data from all PCR-positive patients, $\mathbf{b}$ results corresponding to samples collected in the first week after

a detectable serological response after more than 30 days of evolution [22]. For SARS, all patients developed antibodies [23], but $28 \%$ showed negative IgM after 60 days [24], and most patients had lost the antibody response by six years [25].

However, it is surprising that the large proportion of patients with positive IgG levels in samples were surveyed so close to the first PCR-positive results: $45.0 \%$ within the first 3 days. Some of the patients even debuted with an IgG-positive/ 1st week

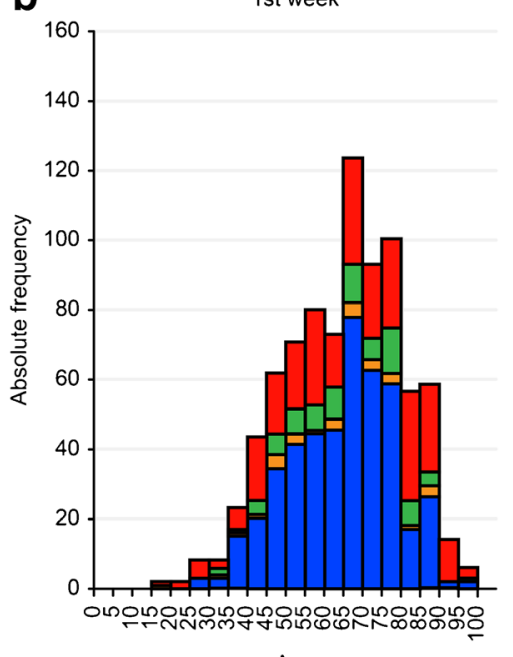

Age 2nd week +

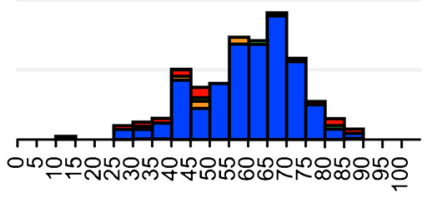

Age $\square$ 1. NEG $\lg$ \& NEG $\lg M+A$
$\square$ 2. NEG $\lg$ \& POS $\lg M+A$
$\square$ 3. POS $\lg$ \& NEG $\lg M+A$
4. POS $\lg G$ \& POS $\lg M+A$

the first PCR result, and $\mathbf{c}$ results corresponding to samples collected later than one week after the first PCR result

IgM + IgA-negative pattern. This finding could be in agreement with previous contact with other coronaviruses showing antigenic similarities with the novel SARS-CoV-2, as has been found by authors studying immune cell responses [26], and it could also be explained by the fact that patients are attending the emergency room and need hospitalization, suggesting advanced disease. However, it is not in agreement with the very low levels of IgG against the spike protein and
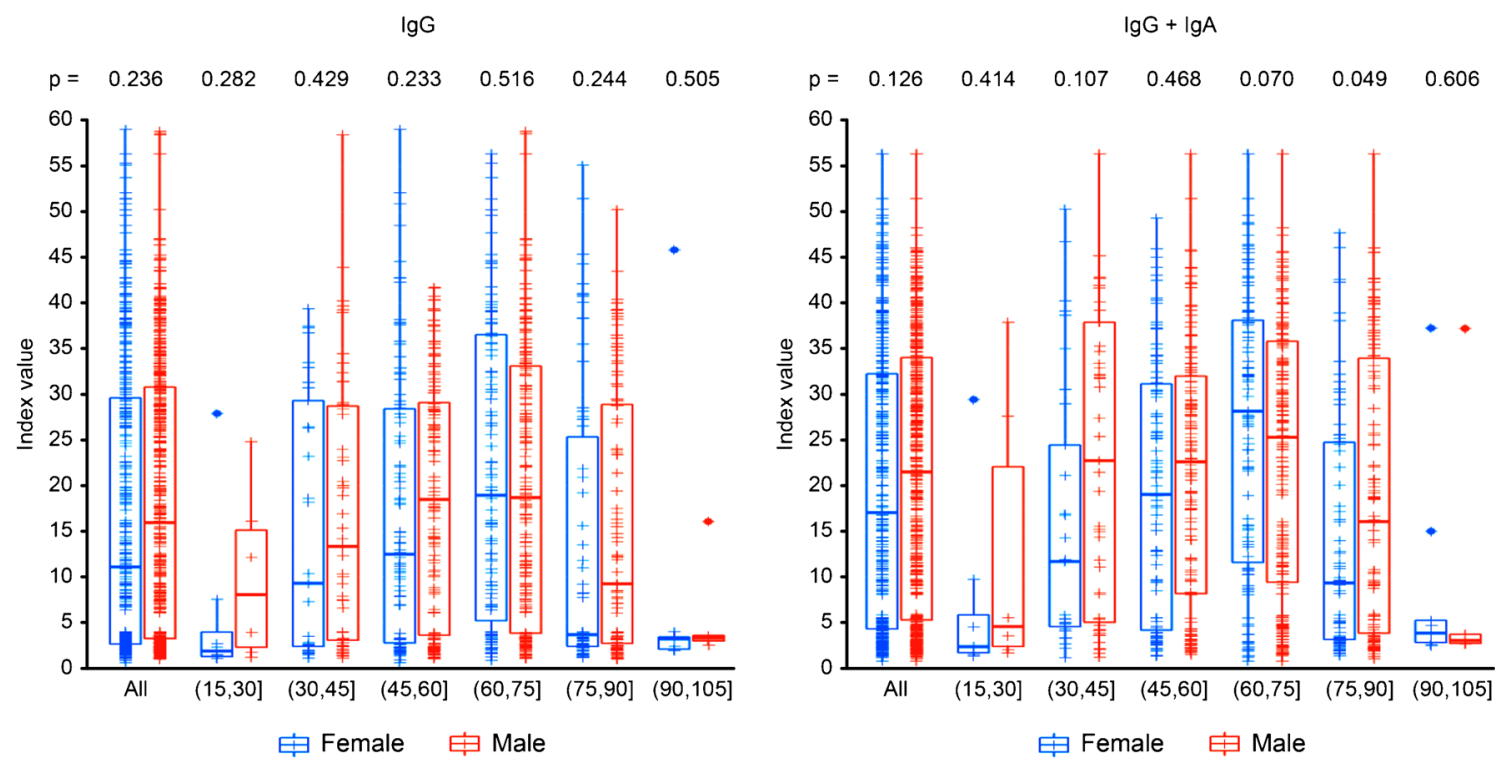

Fig. $3 \mathrm{IgG}$ and IgM + IgA index value (10 X serum/cutoff) boxplot for all PCR-positive patients distinguishing between male and female and grouped by age. Boxes encompass $90 \%$ of the data, and whiskers present the $95 \%$ and $5 \%$ percentiles 
nucleoprotein found in the prepandemic population that translates to the very high specificity of the serological assays used in this and other studies [27].

Due to the large series of sera studied, serological results could be stratified according to the age of the patients. A decreased number of patients with positive serology was observed among the older patients for samples collected early in the disease. However, the proportion increased to near $100 \%$ positivity in all age groups for samples collected in the second week or later after the first positive PCR result. Some authors have suggested a relationship between this delayed response in elderly individuals, with less favorable disease evolution in this population group [28]. For the comparison of serological responses between men and women, no global significant differences were observed either in the proportion of positive results or in the immunoglobulin levels attained in each group. The low number of samples in some of the subgroups may have limited the statistical potency of the comparisons.

In summary, the high values of sensitivity attained in the present study from a relatively early period of time after hospitalization support the use of the evaluated serological assays as supplementary diagnostic tests for the clinical management of COVID-19. The large number of samples gives a particular strength to the evaluation compared with that of others previously published. However, the lack of clinical and evolutionary data of the patients, as well as having used time from positive PCR result rather than time from symptom onset, constitutes its major limitations.

Acknowledgments We acknowledge Vircell SL for their technical support in the serological assays. We also thank all of the healthcare workers their incredible efforts and tireless commitment during this pandemic.

Authors' contributions Ana Fuentes and Esther Serrano-Conde: data collection, sample processing, data analysis, drafting of the manuscript.

Carolina Roldán, Rafael Benito-Ruesca, Gregoria Mejías, Antonio Sampedro, Gabriel March-Roselló, Isabel Fernández-Natal, Juliana Esperalba Esquerra, Mario José Rodríguez, Paula Martínez de Aguirre, Carlos Salas Venero, María Lourdes Roc, Luis Miguel Soria, Mónica Parra-Grande, María Dolores Montero, Ricardo Fernández-Roblas, Francisco Franco-Álvarez de Luna, Carmen Lozano: data collection, sample processing, reviewing of the manuscript.

Federico García: data analysis, drafting of the manuscript, reviewing, and editing of the manuscript.

Funding The ELISA kits for the IgG and IgM + IgA assays were provided by Vircell SL. No additional funding was received.

Data availability Data may be provided upon request to the corresponding author.

\section{Compliance with ethical standards}

Ethical approval, consent to participate, consent to publish Sera were anonymized and sourced from remnant specimens. The Spanish Health Ministry issued a special authorization for the collection of these samples during the pandemic period in Spain to support the evaluation of new diagnostic tests.

Competing interest All authors declare no conflict of interest for the subject of the study

Open Access This article is licensed under a Creative Commons Attribution 4.0 International License, which permits use, sharing, adaptation, distribution and reproduction in any medium or format, as long as you give appropriate credit to the original author(s) and the source, provide a link to the Creative Commons licence, and indicate if changes were made. The images or other third party material in this article are included in the article's Creative Commons licence, unless indicated otherwise in a credit line to the material. If material is not included in the article's Creative Commons licence and your intended use is not permitted by statutory regulation or exceeds the permitted use, you will need to obtain permission directly from the copyright holder. To view a copy of this licence, visit http://creativecommons.org/licenses/by/4.0/.

\section{References}

1. Li Q (2020) An outbreak of NCIP (2019-nCoV) infection in China-Wuhan, Hubei Province, 2019- 2020. China CDC Wkly 2:79-80

2. Guo L, Ren L, Yang S, et al. 2020. Profiling early humoral response to diagnose novel coronavirus disease (COVID-19). Clin Infect Dis ciaa 310. doi:https://doi.org/10.1093/cid/ciaa310.

3. Li Q, Guan X, Wu P et al (2020) Early transmission dynamics in Wuhan, China, of novel coronavirus-infected pneumonia. N Engl J Med 382:1199-1207

4. Lu R, Zhao X, Li J et al (2020) Genomic characterisation and epidemiology of 2019 novel coronavirus: implications for virus origins and receptor binding. Lancet 395:565-574

5. Corman VM, Landt O, Kaiser M et al (2020) Detection of 2019 novel coronavirus (2019-nCoV) by real-time RT-PCR. Euro Surveill 25:2000045

6. Rothe C, Schunk M, Sothmann P et al (2020) Transmission of 2019-nCoV infection from an asymptomatic contact in Germany. N Engl J Med 382:970-971

7. Okba NMA, Müller MA, Li W et al (2020) Severe acute respiratory syndrome coronavirus 2-specific antibody responses in coronavirus disease patients. Emerg Infect Dis 26:1478-1488

8. WHO (2020) Population-based age-stratified seroepidemiological investigation protocol for COVID-19 virus infection. World Health Organization, Geneva

9. Liu W, Liu L, Kou G et al (2020) Evaluation of nucleocapsid and spike protein-based enzyme-linked immunosorbent assays for detecting antibodies against SARS-CoV-2. J Clin Microbiol 58: $\mathrm{e} 00461-\mathrm{e} 00420$

10. Sun B, Feng Y, Mo X et al (2020) Kinetics of SARS-CoV-2 specific IgM and IgG responses in COVID-19 patients. Emerg Microbes Infect 9:940-948

11. Long QX, Liu BZ, Deng HJ et al (2020) Antibody responses to SARS-CoV-2 in patients with COVID-19. Nat Med 26:845-848

12. Montesinos I, Gruson D, Kabamba B et al (2020) Evaluation of two automated and three rapid lateral flow immunoassays for the detection of anti-SARS-CoV-2 antibodies. J Clin Virol 128:104413

13. Zhao J, Yuan Q, Wang H, et al. 2020. Antibody responses to SARS-CoV-2 in patients of novel coronavirus disease 2019. Clin Infect Dis ciaa344. doi:https://doi.org/10.1093/cid/ciaa344. 
14. Kohmer N, Westhaus S, Rühl C et al (2020) Clinical performance of different SARS-CoV-2 IgG antibody tests. J Med Virol. https:// doi.org/10.1002/jmv.26145

15. Bryan A, Pepper G, Wener MH, et al. 2020. Performance characteristics of the abbott architect SARS-CoV-2 IgG assay and seroprevalence in Boise, Idaho. J Clin Microbiol JCM.00941-20. doi: https://doi.org/10.1128/jcm.00941-20.

16. Theel ES, Harring J, Hilgart H, et al. 2020. Performance characteristics of four high-throughput immunoassays for detection of IgG antibodies against SARS-CoV-2. J Clin Microbiol JCM.01243-20. doi:https://doi.org/10.1128/jcm.01243-20.

17. Tang MS, Hock KG, Logsdon NM, et al. 2020. Clinical performance of two SARS-CoV-2 serologic assays. Clin Chem hvaa120. doi:https://doi.org/10.1093/clinchem/hvaa120.

18. Ma H, Zeng W, He H, et al. 2020. COVID-19 diagnosis and study of serum SARS-CoV-2 specific IgA, IgM and IgG by chemiluminescence immunoanalysis. medRxiv: 2020.2004.2017.20064907.

19. Yu HQ, Sun BQ, Fang ZF et al (2020) Distinct features of SARSCoV-2-specific IgA response in COVID-19 patients. Eur Respir J 2001526. https://doi.org/10.1183/13993003.01526-2020

20. Zhang G, Nie S, Zhang Z et al (2020) Longitudinal change of severe acute respiratory syndrome coronavirus 2 antibodies in patients with coronavirus disease 2019. J Infect Dis 222:183-188

21. Yang HS, Racine-Brzostek SE, Lee WT et al (2020) SARS-CoV-2 antibody characterization in emergency department, hospitalized and convalescent patients by two semi-quantitative immunoassays. Clin Chim Acta 509:117-125
22. Corman VM, Albarrak AM, Omrani AS et al (2016) Viral shedding and antibody response in 37 patients with middle east respiratory syndrome coronavirus infection. Clin Infect Dis 62:477-483

23. Chan KH, Cheng VC, Woo PC et al (2005) Serological responses in patients with severe acute respiratory syndrome coronavirus infection and cross-reactivity with human coronaviruses 229E, OC43, and NL63. Clin Diagn Lab Immunol 12:1317-1321

24. Shi Y, Wan Z, Li L et al (2004) Antibody responses against SARScoronavirus and its nucleocaspid in SARS patients. J Clin Virol 31: $66-68$

25. Tang F, Quan Y, Xin ZT et al (2011) Lack of peripheral memory B cell responses in recovered patients with severe acute respiratory syndrome: a six-year follow-up study. J Immunol 186:7264-7268

26. Grifoni A, Weiskopf D, Ramirez SI, et al. 2020. Targets of T cell responses to SARS-CoV-2 coronavirus in humans with COVID-19 disease and unexposed individuals. Cell 181:1489-1501.e15.

27. Kontou PI, Braliou GG, Dimou NL et al (2020) Antibody tests in detecting SARS-CoV-2 infection: a meta-analysis. Diagnostics (Basel) 10. https://doi.org/10.3390/diagnostics10050319

28. Montecino-Rodriguez E, Berent-Maoz B, Dorshkind K (2013) Causes, consequences, and reversal of immune system aging. $\mathrm{J}$ Clin Invest 123:958-965

Publisher's note Springer Nature remains neutral with regard to jurisdictional claims in published maps and institutional affiliations. 